\title{
PARA UM MAPA DAS FRONTEIRAS E DAS PONTES NA INVESTIGAÇÃO EM DIDÁTICA DA GRAMÁTICA
}

RESUMO: Com o presente artigo, propomos contribuir para uma clarificação conceptual do campo da investigação em didática da gramática, aprofundando a reflexão em torno das fronteiras entre linguística e ensino da língua. Esta reflexão será ilustrada pela consideração de dois percursos de investigação sobre relações entre gramática e competência de escrita, por um lado, e entre gramática e competência de leitura, por outro. Dos resultados destes trabalhos - que disponibilizam informação sobre o conhecimento linguístico em estabilização em idade escolar - emergem ainda dois desafios cruciais para a investigação em didática da gramática: o problema da validação das propostas didáticas decorrentes da investigação e o problema da disseminação dos resultados. Nas considerações finais, debatem-se estes problemas à luz de uma perspetiva de trabalho em permanente interação entre três polos: investigação, ensino e aprendizagem da língua e formação de professores.

PALAVRAS-CHAVE: gramática, consciência linguística, conhecimento explícito da língua, escrita, leitura

ABSTRACT: In the present article, we propose to contribute to a conceptual clarification of the field of research in grammar teaching and learning by reflecting upon the borders between linguistics and language teaching. This reflection will be illustrated by two studies which investigate relations between grammar and writing, on the one hand, and grammar and reading, on the other. Based on the results of these studies, which provide information on the nature of linguistic knowledge 
developing during school-age, two other fundamental questions arise: the problem of the validation of didactic proposals resulting from research and the problem of the dissemination of results. In the final remarks, these problems are debated from a perspective in which three poles - research, language teaching and learning and teacher training - are in permanent interaction.

KEYWORDS: grammar, linguistic awareness, explicit knowledge of language, writing, reading

\section{1 - Introdução}

$\mathrm{Na}$ encruzilhada de critérios que validam qualquer trabalho de investigação, encontra-se a definição do seu enquadramento teórico ou, enunciando o problema de forma mais coloquial, a possibilidade de o esclarecer: "Este trabalho situa-se no quadro X". Ora, relativamente à investigação sobre didática da gramática - sobre os processos de ensino e de aprendizagem da gramática na escola -, vários autores têm apontado a falta de "clareza conceptual» deste campo de estudos (Fontich 2016, 2018; Rijt \& Coppen 2017). Ainda que esta questão possa ser vista como herança da configuração epistemológica da(s) didática(s) da(s) língua(s), o problema da fronteira entre investigação em linguística e investigação em ensino da gramática assume contornos bastante específicos, que justificam a finalidade do presente artigo: contribuir para uma clarificação conceptual do campo de investigação em didática da gramática. No segundo ponto, aprofundar-se-á a reflexão em torno da definição das fronteiras entre linguística e ensino da língua e, nos pontos seguintes, esta reflexão será ilustrada pela consideração dos limites e traços definidores de dois percursos de investigação: um sobre gramática e escrita e outro sobre gramática e leitura. Da reflexão crítica relativamente a resultados de investigação sobre as relações entre conhecimento explícito da língua, desenvolvimento da competência de escrita e desenvolvimento da competência de compreensão leitora, emergem ainda dois desafios cruciais: o problema da validação das propostas didáticas decorrentes da investigação e o problema da disseminação dos resultados da investigação, brevemente considerados enquanto condição para a definição de um campo específico de estudos sobre didática da gramática. Nas considerações finais, retomar-se-ão estas questões numa perspetiva de trabalho em permanente interação entre três polos indissociáveis - investigação em didática, ensino e aprendizagem da língua e formação de professores. 


\section{2 - O problema das fronteiras}

Ainda que o tema específico deste artigo se circunscreva à didática da gramática, o reconhecimento de um campo de investigação neste domínio pode ser incluído na necessidade de identificação de um campo de investigação em didática da língua ou das línguas, questão que tem sido objeto de reflexão por diferentes autores (Alarcão 2010; Alarcão et al. 2010; Camps 2012; Costa, Rodrigues \& Sebastião 2018). Vários são os sintomas que evidenciam falta de clareza na perceção da didática como um campo próprio de investigação. Por exemplo, a diversidade de designações das especialidades de doutoramentos sobre linguística e ensino - didática de línguas, linguística e ensino, linguística educacional - ilustra a dificuldade em estabelecer fronteiras entre o que é investigação em linguística e o que é investigação em ensino da língua. Por outro lado, as designações de unidades curriculares da área da linguística e ensino em diferentes cursos de formação de educadores e professores, nas instituições de ensino superior, bem como a diversidade de conteúdos de formação nas unidades curriculares de didática manifestam uma vasta pluralidade de entendimentos do que entra e deve ser valorizado na formação didática dos futuros profissionais de educação.

A par da disparidade de configurações disciplinares, contudo, o aumento da produção científica sobre ensino e aprendizagem do Português é inegável nas últimas décadas. A publicação de novas obras e estudos foi, em grande medida, impulsionada pela formação contínua no âmbito da Terminologia Linguística para os Ensinos Básico e Secundário (TLEBS) e, mais tarde, do Dicionário Terminológico (DT) (DGIDC 2008), do Programa Nacional do Ensino do Português (PNEP) e da implementação dos Programas de 2009 (DGIDC 2009). A regulamentação dos cursos de mestrados em ensino, com a obrigatoriedade de conclusão do segundo ciclo de formação através de provas de mestrado e de relatórios de projeto de investigação, contribuiu igualmente para um aumento da produção de investigação em ensino, incluindo temas específicos da didática das línguas. Entre estes estudos, alguma investigação, com análise de metadados, aponta para a urgência de teorização sobre a reconfiguração epistemológica da didática da língua (Alarcão et al. 2010).

Se estes fatores indiciam, por um lado, dispersão e falta de clareza na circunscrição do campo de estudos, permitem, por outro, reconhecer uma alteração de paradigma de uma didática do Português subsidiária de outros campos de conhecimento (dos diferentes ramos da linguística, da psicolinguística, da literatura) para um campo autónomo de investigação e produção de conhecimento. Esta mesma perspetiva é comum a outros contextos e a outras didáticas. Enfrentando o problema das fronteiras, Camps (2012: 27) defende a existência de investigação em didática da língua 
que, para além de espaço de interseção e de articulação com a investigação em linguística, se tem vindo a consagrar como «campo de conhecimento e investigação específico», no qual se deve focar a questão da delimitação de fronteiras, não nas relações com outras áreas de estudo, mas no objeto específico da investigação em didática da língua: os processos de desenvolvimento e de aprendizagem da(s) língua(s) e os processos do seu ensino.

Considerando concretamente os processos de desenvolvimento linguístico, ensino e aprendizagem da gramática da língua, a questão da fronteira com uma teoria linguística que explique a aquisição e desenvolvimento da linguagem é inultrapassável. A conceção do ensino da gramática, naturalmente, está arraigada à forma como se concebe a faculdade da linguagem e a aquisição da(s) primeira(s) (e segundas) língua(s). Referindo a pluralidade de teorias linguísticas que influenciam o ensino da gramática, Fontich (2018: 1) junta-se aos diferentes autores que «have noted a lack of conceptual clarity in the field of L1 grammar instruction». Para vários autores, algumas teorias são mais adequadas do que outras a uma pedagogia para a aprendizagem da gramática pelo papel que conferem à interação linguística (Fontich \& García-Folgado 2018; Rijt \& Coppen 2017). Contudo, o cerne do desentendimento parece estar na forma como cada autor interpreta o peso que diferentes teorias atribuem ao papel da interação. É comum encontrar, em trabalhos que se inscrevem numa perspetiva sociocultural ou em perspetivas interacionistas, a ideia de que as abordagens inatistas não consideram as interações sociais uma dimensão crucial do desenvolvimento linguístico (Fontich 2018). É igualmente frequente encontrar, em trabalhos sobre desenvolvimento linguístico numa perspetiva generativista, a preocupação em esclarecer o papel crucial que a exposição à língua desempenha no processo de aquisição (Cook 1988; Costa, Costa \& Gonçalves 2017).

A conceção de aquisição da linguagem e o papel da interação são, efetivamente, centrais para o debate sobre teorias linguísticas e ensino da língua e sobre a reconfiguração da didática da língua e, em particular, da didática da gramática. A questão das fronteiras com as teorias linguísticas pode ser abordada de forma mais inclusiva, ganha pela clarificação de três conceitos-chave para o debate: gramática, aplicação e interação. Uma visão mais eclética destes conceitos no conjunto das teorias que interpretam a linguagem humana permite perceber áreas de confluência determinantes na definição do que é específico dos processos de ensino e de aprendizagem da gramática em contexto escolar. Em concreto, mesmo partindo de uma explicação inatista para o processo de aquisição da linguagem humana, a interação assume uma função crítica na fixação dos parâmetros das línguas naturais. $\mathrm{O}$ facto de que a faculdade humana da linguagem se explique em 
grande medida como uma instância biológica, inata, não exclui a importância das interações sociais na aquisição da língua. Vivian Cook (1988) ilustra o papel da interação com o meio através da imagem das condições de crescimento de uma planta:

A seed is planted in the ground, which grows and eventually flowers; the growth would not take place without the environment; it needs water, minerals and sunshine; but the entire possibility of the plant is inherent in the seed; the environment only dictates the extent to which its inherited potentialities are realized. Knowledge of language needs experience to mature; without it nothing would happen; but the entire potential is there from the start.

(Cook 1988: 72)

Fundamentalmente, continuar a transpor para o campo da didática as velhas guerras entre teorias linguísticas mais não é do que manter a lógica aplicacionista da linguística na didática da língua, ideia que se retomará nos pontos seguintes.

Desde o início deste artigo que se adotou uma expressão pouco usual, inexistente em livros de referência sobre didática da língua (Amor 1993; Cassany, Luna \& Sanz 1994): a expressão "didática da gramática”. Através deste termo, pretendeu-se fazer referência aos processos de ensino e aos processos de aprendizagem envolvidos no conhecimento sobre a língua em contexto escolar. O problema da plurissignificação do termo "gramática" situa-se no cerne da questão das fronteiras entre teoria linguística e didática. Em linguística formal, gramática é, antes de mais, o conhecimento que qualquer falante detém da sua língua materna, sem precisar de instrução formal, portanto, independentemente do ensino da gramática na escola. Esta aceção difere substancialmente do conceito tradicionalmente atribuído a gramática enquanto corpo de conhecimentos a estudar na disciplina de língua materna. Por ter sido este o termo que vingou no recente Programa e Metas (DGE, 2015), adota-se "gramática" no sentido de «conhecimento escolar», por razões de transparência na comunicação com professores, futuros professores e alunos do ensino básico e secundário. No entanto, marcando claramente a fronteira com uma perspetiva mais tradicional, a gramática que se ensina e aprende na escola deve corresponder a um conhecimento explícito da língua. Na sua melhor definição, que é a do antigo Currículo Nacional do Ensino Básico português:

Entende-se por conhecimento explícito o conhecimento refletido, explícito e sistematizado das unidades, regras e processos gramaticais da língua. Esta competência implica o desenvolvimento de processos metacognitivos, quase sempre dependentes da instrução formal, e permite aos falantes o controlo das regras que usam e a seleção das estratégias mais adequadas à compreensão e expressão em cada situação de comunicação.

(DEB, 2001: 32). 
No percurso de explicitação e sistematização do conhecimento linguístico, diferentes autores identificam fases intermédias de consciência linguística, que evidenciam estabilização de um dado domínio do conhecimento implícito e permitem torná-lo consciente. Nesta perspetiva, aprender gramática na fase de escolarização corresponde a uma progressiva consciencialização da língua que se usa. Em autores de quadros teóricos diferentes, encontram-se modelos de representação de diferentes graus de consciência linguística. Entre os modelos da psicologia, na proposta de Karmiloff-Smith (1992), distinguem-se quatro níveis de representação do conhecimento linguístico: (i) conhecimento implícito, que suporta as primeiras manifestações verbais das crianças; (ii) conhecimento explícito primário, um conhecimento semiconsciente que decorre do desenvolvimento do conhecimento implícito; (iii) um conhecimento explícito secundário, que se manifesta pelo acesso consciente ao conhecimento linguístico e, finalmente, (iv) um grau superior de conhecimento explícito, que envolve a recodificação do conhecimento num código mais abstrato ou, por outras palavras, a capacidade de referir linguagem com metalinguagem.

Entre estudos da área da linguística, autores como Costa, Costa \& Gonçalves (2017) ou Freitas, Gonçalves \& Duarte (2010), de forma similar, distinguem graus de conhecimento linguístico, no contínuo conhecimento linguístico implícito - consciência linguística - conhecimento explícito da língua. O conhecimento implícito consiste no conhecimento intuitivo das estruturas da língua e desenvolve-se espontaneamente a partir da interação entre a faculdade da linguagem e o input linguístico fornecido pelos contextos em que as crianças estão envolvidas (a interação com o meio é essencial, como se referiu antes). O conhecimento implícito pode ser entendido como a gramática mental de qualquer falante. Do uso das estruturas linguísticas que se adquirem espontaneamente, emergem capacidades de manipulação e referência que evidenciam algum grau de consciência da língua. Em diferentes estádios, tipos distintos de consciência linguística - fonológica, sintática, lexical - vão-se desenvolvendo, particularmente em contextos de aprendizagem formal. Finalmente, por conhecimento explícito da língua, entende-se a «progressiva consciencialização e sistematização do conhecimento implícito no uso de língua» (Sim-Sim, Duarte \& Ferraz 1997: 30). Na escola, esta competência deve ser promovida de forma sistemática e intencional, precisando, para isso, de uma didática que ampare a natureza específica deste conhecimento matricial nas línguas.

Outro problema das fronteiras, como se mencionou antes, prende-se com a ideia de «aplicação» das teorias linguísticas mais atualizadas ao ensino. A linguística aplicada dominou, e ainda domina, algumas áreas da didática da língua desde os anos 1960. Demarcando-se desta perspetiva, Spolsky 
introduz em 1974 o termo "linguística educacional" para designar um campo de investigação específico. Ainda que se reconheçam dificuldades na delimitação deste campo (Ucelli \& Snow 2008), uma vez que ele se situa na confluência de diferentes disciplinas, é na rejeição de uma lógica aplicacionista que ele se define em primeiro lugar: «[w]e seek then not apply linguistics, but to derive from its many branches and from other fields that study language, the knowledge that will help in developing the language capacity of others» (Spolsky 1999: 2). Numa das suas definições de linguística educacional, aliás, o autor atribui à linguística aplicada a criação de alguns «monstros» (Spolsky 2008: 1), que podemos rever na gramática que uma certa geração teve de aprender, com a reprodução incompreensível do modelo de comunicação de Jakobson ou as representações de frases em árvore. Portanto, e como para Spolsky (1978: 1), sendo evidente que «a linguística é relevante para a educação», em particular para a didática da gramática, esta relação não é direta, pelo que é necessário estabelecer as fronteiras entre modelos teóricos e práticas de ensino.

Considerando que as conceções de "linguagem" e "aquisição da linguagem" são determinantes para o entendimento dos processos envolvidos no ensino e na aprendizagem da gramática, assume-se um entendimento de linguagem como «faculdade mental inata, exclusiva da espécie humana, que permite a qualquer indivíduo adquirir, de forma espontânea (isto é, sem aprendizagem formal), a língua a que está exposto desde o nascimento e que virá a ser a sua língua materna» (Costa, Costa \& Gonçalves 2017: 417). A adoção destes pressupostos não significa, naturalmente, uma transposição dos instrumentos da linguística formal para o campo do ensino. Como antes ficou expresso, esta perspetiva de linguagem humana não exclui o papel da interação comunicativa na aprendizagem das línguas e, em concreto, na aprendizagem da gramática. Pelo contrário, e como exemplificaremos no ponto seguinte deste artigo, a diversificação de experiências de usos de língua constitui um aspeto assumidamente central em dois percursos de investigação - Costa (2010) e Batalha (2017) - que estudam relações entre gramática e o desenvolvimento das competências de escrita e de leitura em contexto escolar.

\section{3 - Percursos de investigação em didática da gramática}

O objeto e os objetivos dos trabalhos de Costa (2010) e Batalha (2017) são comuns: estudar relações entre conhecimento explícito da língua e desenvolvimento da competência de escrita, no primeiro trabalho, e da competência de leitura, no segundo. Trata-se, portanto, de estudos em que o ensino e a aprendizagem da gramática cumprem objetivos de tipo instrumental, de acordo com a proposta de Duarte (1998). 
Também é comum a ambos os estudos a preocupação que manifestam em conciliar, em termos metodológicos, os objetivos da investigação em linguística com propostas didaticamente adequadas à sala de aula. Desta preocupação, emerge o problema das fronteiras entre investigação linguística e investigação em ensino. Por exemplo, as sequências didáticas dos dois trabalhos foram integradas na planificação regular dos professores para as suas turmas como forma de articular e fazer interagir os objetivos de investigação com o trabalho de professores e alunos - com uma abordagem tão naturalista quanto possível, sendo esta uma característica determinante na metodologia destes estudos. Porém, para ser didática e pedagogicamente adequada, a configuração das tarefas nem sempre cumpriu os requisitos ideais das metodologias experimentais em aquisição da linguagem. Paralelamente, porém, nos dois trabalhos, o recurso a desenhos de inspiração experimental (pré-teste/pós-teste) e a análises de pendor quantitativo e estatístico como critério de validação de resultados são opções mais alinhadas com práticas de investigação em linguística.

No que se refere às propostas didáticas, em ambos os estudos se recorre ao modelo de laboratório gramatical, de acordo com as etapas propostas em tarefas para o desenvolvimento da consciência linguística no 1. ${ }^{\circ}$ ciclo (Duarte 2008) e em tarefas sobre contextos de uso obrigatório do conjuntivo (Duarte 1992). Estas propostas são concebidas como estratégias de explicitação do conhecimento intuitivo dos alunos, assentes na observação e manipulação de dados linguísticos para a deteção de regularidades e formulação de generalizações. O laboratório gramatical partilha estas características com outros trabalhos sobre ensino da gramática, como os «linguistic inquiries», de projetos conduzidos em escolas americanas por Wayne O'Neil e colegas (O'Neil 2010; Honda, O’Neil \& Pippin 2010), ou como as propostas de «construção de gramáticas» de Oliveira \& Quarezemin (2016), no contexto brasileiro. Também estabelecem pontes com outras abordagens didáticas que seguem os princípios pedagógicos do questionamento de Bruner, na aprendizagem pela descoberta (Hudson 1992). Finalmente, destaque-se que, com este tipo de abordagem, promovendo o uso de capacidades de reflexão metalinguística e metacognitiva, se criam condições para que os alunos contactem com o método científico, o que permite estabelecer uma outra ponte, com um ensino da gramática como «atividade metalinguística», de inspiração vigotskiana, que parte das conceções espontâneas das crianças, e das capacidades precoces para referir linguagem através da linguagem, na construção de conhecimento gramatical (Camps 2014; Fontich 2018). No fundo, e (quase) independentemente do modelo teórico usado para explicar a linguagem, o que é comum a estas propostas é um entendimento de gramática como "atividade reflexiva". 


\section{1 - Gramática e escrita}

Em Costa (2010), sobre as relações entre conhecimento explícito da língua e desenvolvimento da escrita, estudou-se especificamente o conhecimento de adversativas e concessivas e a escrita de textos de opinião. Deste trabalho, destacam-se apenas algumas ideias que podem ajudar a ilustrar características da investigação em didática da gramática. A parte empírica do trabalho teve três fases: diagnóstico, intervenção e avaliação. Na fase de diagnóstico, a que mais proximidade teve com um estudo sobre a aquisição de concessivas, pretendeuse caracterizar o conhecimento linguístico sobre estruturas contrastivas (adversativas e concessivas) através de três testes: um de compreensão oral de um texto, outro de produção induzida de frases e outro de produção em textos de opinião. Todos os testes tiveram o formato de tarefas que puderam ser integradas no trabalho pedagógico com as turmas. Do resultado deste diagnóstico, concluiu-se que o conhecimento de diferentes tipos de concessivas estava ainda em estabilização ao longo dos primeiros anos da escolaridade. No gráfico 1 , os resultados das percentagens de acerto evidenciam que há crescimento na compreensão oral de contrastivas ao longo da escolaridade básica.

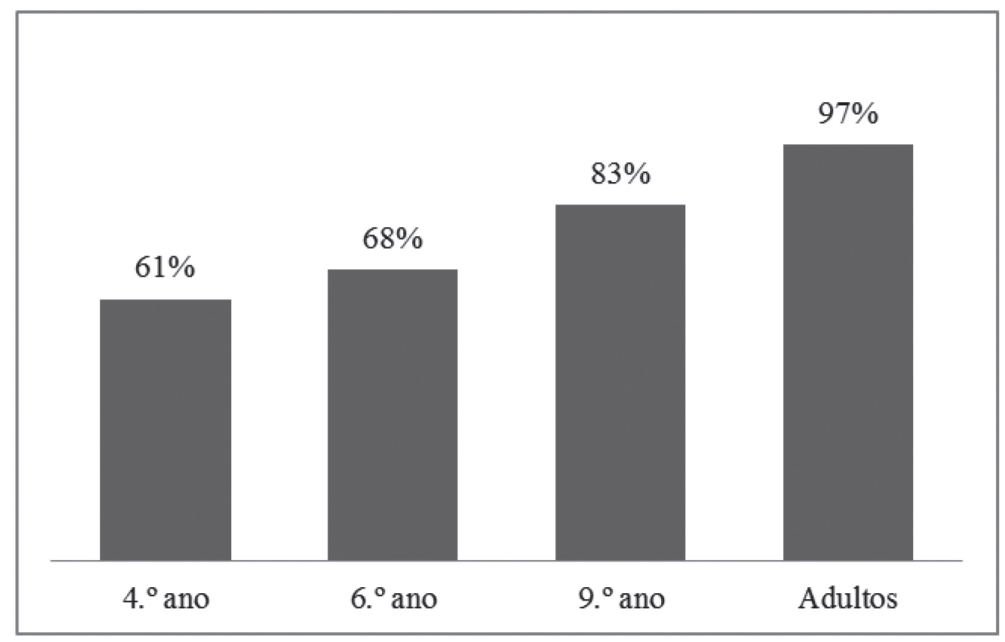

Gráfico 1 - Compreensão oral de texto

Uma silhueta semelhante figura no gráfico 2, que sistematiza as percentagens de acerto no teste de produção induzida de frases com conectores contrastivos nos três ciclos de escolaridade, em comparação com o grupo de controlo de adultos escolarizados. 


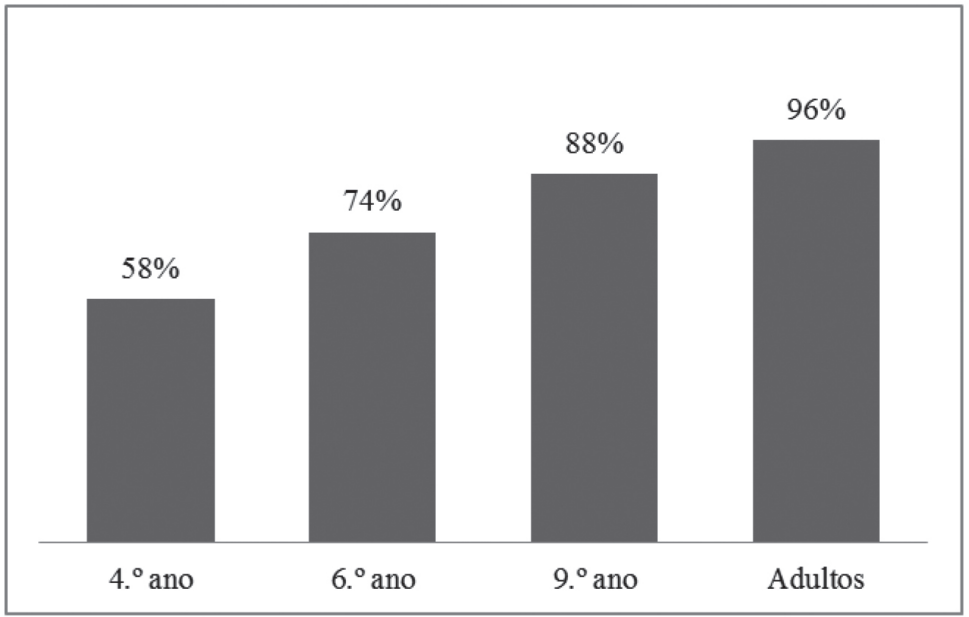

Gráfico 2 - Produção induzida de contrastivas

Os resultados deste diagnóstico apoiaram a decisão relativamente ao ano de escolaridade em que se deveria desenvolver a intervenção educativa. Como era preciso circunscrever o estudo, optou-se por fazer a intervenção em gramática e escrita na fase em que o conhecimento linguístico estava bastante estabilizado e poderia ser mobilizado. Os alunos mais velhos, do 9. ${ }^{\circ}$ ano, apesar de terem resultados de compreensão e produção induzida de frases próximos do padrão adulto, em situações de escrita de texto de opinião não mobilizavam esse capital de conhecimento implícito, usando quase sempre o mas adversativo. Em concreto, nos textos de opinião escritos na fase de diagnóstico, num total de 31 frases complexas com conectores contrastivos, 25 frases (81\%) eram adversativas e apenas $6(9 \%)$ eram concessivas.

A fase de intervenção, desenvolvida em duas turmas de $9 .^{\circ}$ ano, seguiu o modelo didático de «chantier» de escrita, de acordo com o proposto no projeto de investigação-ação coordenado por Josette Jolibert (Jolibert (coord.) 1988). Com este modelo, centrado na pedagogia de trabalho de projeto, procurou-se enquadrar a escrita escolar em interações significativas para os alunos, nas quais fossem claros os objetivos da produção dos seus textos. As atividades de sistematização metalinguística, uma das fases previstas nos «chantiers», adotaram o formato de laboratório gramatical sobre propriedades sintáticas, semânticas e discursivas de adversativas e concessivas. Por outras palavras, o ensino da gramática foi enquadrado por práticas pedagógicas conscientes da centralidade das interações discursivas - orais e escritas - vividas no contexto escolar. 
A avaliação (em pós-teste) dos textos de opinião escritos algum tempo após a intervenção e a avaliação de conhecimento sobre gramática evidenciaram, nas turmas em que houve intervenção, e em contraste com o grupo de controlo ${ }^{1}$, que os alunos usavam mais estruturas contrastivas e conectores mais diversificados e tiveram melhores resultados em perguntas sobre gramática num teste de final de período. O gráfico 3 ilustra estes resultados, apresentando uma comparação das frequências de ocorrência de conectores antes e após a intervenção².

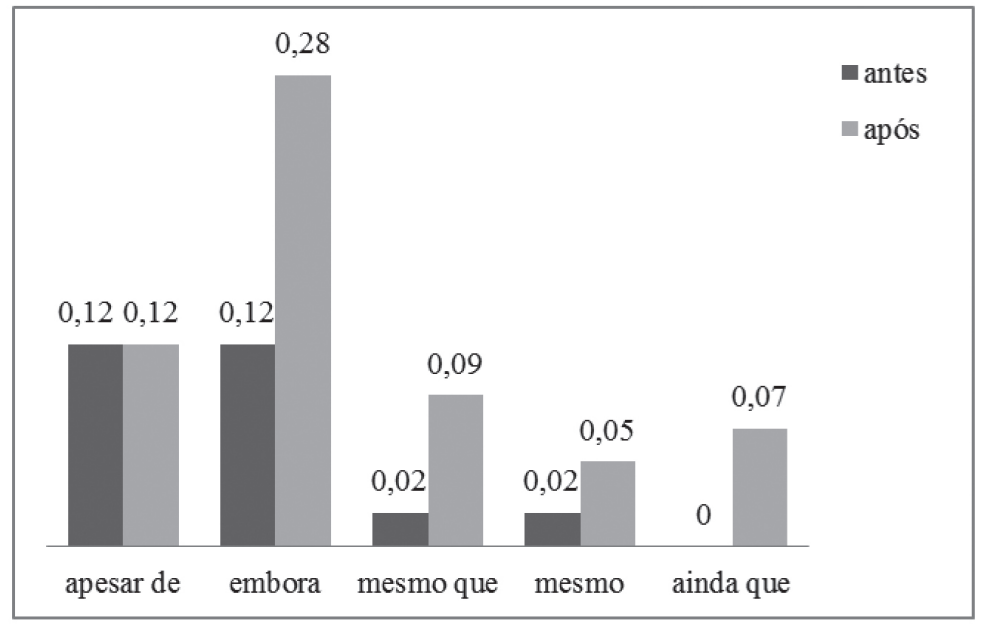

Gráfico 3 - Produção de conetores concessivos antes e após a intervenção

O facto de a intervenção se ter limitado ao $9 .^{\circ}$ ano, quando os alunos já evidenciavam resultados acima dos $75 \%$ de acertos nos testes de compreensão oral e de produção induzida, muito próximos do perfil do adulto, não significa que se considere didaticamente irrelevante ou inadequado trabalhar sobre estas estruturas desde o $1 .^{\circ}$ ciclo.

Atendendo aos resultados do $4 .^{\circ}$ ano, na fase de diagnóstico, é interessante perceber que o conhecimento sobre concessivas não está ainda completo, está em estabilização ao longo da escolaridade e, para expressar contraste, as crianças usam o que já têm disponível na sua gramática, no seu conhecimento implícito desde cerca dos dois anos: as adversativas de mas (Costa, Alexandre, Santos \& Soares 2008). As interações discursivas

\footnotetext{
${ }^{1}$ No grupo de controlo da fase de intervenção, constituído por uma terceira turma de $9 .^{\circ}$ ano em que não houve intervenção didática com «chantier» e «oficina gramatical», nos textos recolhidos em pré e pós-teste, os resultados não apresentam diferenças, senão na ocorrência de mesmo que no segundo conjunto de produções.

${ }^{2}$ A frequência de ocorrência de cada conector foi calculada através da divisão do número de conectores pelo número de textos para cada nível de ensino.
} 
a que as crianças são expostas em contexto escolar, e nas quais devem progressivamente assumir o protagonismo em percursos de aprendizagem ativa, são cruciais para a promoção do desenvolvimento linguístico de estruturas tardias. Estas estruturas, como é o caso das concessivas, não são frequentes nos registos de língua familiares (com diferenças sociolinguísticas assinaláveis). Da sua aquisição, depende o domínio de registos de língua fundamentais ao sucesso escolar. Por isso, a escola, nos primeiros anos, tem de intencionalmente promover não só práticas discursivas desafiantes, mas também um ensino da gramática assente no desenvolvimento da consciência sintática e semântica. Outro exemplo desta dimensão do ensino da gramática encontra-se na secção seguinte.

\section{2 - Gramática e leitura}

No trabalho de Batalha (2017) sobre relações entre gramática e leitura, estudou-se a compreensão de relações anafóricas envolvendo diferentes tipos de pronomes, nomeadamente pronomes pessoais, demonstrativos e relativos. Considerando a importância do processamento deste tipo de estruturas na construção de uma representação mental adequada dos textos lidos, especialmente em leitores mais jovens (Cain \& Oakhill 2009), assim como as relações que a investigação tem estabelecido entre nível de conhecimento gramatical e compreensão leitora (por exemplo, para o português, Costa 1991; Leal \& Roazzi 1999), desenvolveu-se um estudo com os seguintes objetivos: (i) diagnosticar o conhecimento linguístico de alunos em diferentes momentos do ensino básico quanto à compreensão de pronomes na leitura; (ii) intervir didaticamente face aos resultados obtidos no diagnóstico, através da promoção de atividades visando o desenvolvimento da consciência linguística e do conhecimento explícito sobre relações anafóricas e, mais concretamente, o desenvolvimento de estratégias de identificação de antecedentes de pronomes; (iii) e avaliar efeitos da intervenção didática na compreensão de pronomes na leitura, comparando desempenhos antes e após a intervenção implementada.

Para dar cumprimento a estes objetivos, o estudo empírico, tal como na investigação de Costa (2010), foi desenvolvido em três fases - diagnóstico, intervenção e avaliação de resultados. Na fase de diagnóstico, procurando obter-se dados sobre a compreensão de pronomes na leitura ao longo do ensino básico, aplicou-se a três grupos de alunos - de $4 .^{\circ}, 6 .^{\circ}$ e $8 .^{\circ}$ anos - e a um grupo de controlo de adultos escolarizados uma primeira prova (pré-teste) com quatro textos e uma tarefa de identificação de antecedentes de pronomes. A partir dos resultados obtidos, selecionou-se o grupo de alunos de $4 .^{\circ}$ ano para participar como grupo experimental na intervenção didática, concebida e implementada com o objetivo de promover o desenvolvimento da consciência e da explicitação linguística sobre relações anafóricas e, em particular, sobre aquelas que envolvem dependência referencial. A intervenção, que seguiu o 
formato de laboratório gramatical, como anteriormente foi referido, centrou-se sobre propriedades sintáticas, semânticas e discursivas dos pronomes enquanto expressões anafóricas que não apresentam um valor referencial próprio e sobre a natureza dos antecedentes a que os pronomes se podem referir. A terceira fase do estudo, de avaliação da intervenção, consistiu na aplicação de uma prova (pós-teste) semelhante à usada no diagnóstico, com quatro textos e uma tarefa de identificação de antecedentes. Os desempenhos dos alunos do grupo experimental foram posteriormente comparados com os de um grupo de controlo, constituído por alunos do mesmo ano de escolaridade, mas que não foi sujeito à intervenção. Por último, para se avaliar possíveis efeitos da intervenção didática na compreensão da leitura, procedeu-se também à comparação dos desempenhos dos alunos do grupo experimental no pós-teste com os desempenhos na prova nacional de Português de $4 .^{\circ}$ ano.

Como se apresenta no gráfico 4 , globalmente, os resultados da fase de diagnóstico mostram que a compreensão de relações anafóricas na leitura e, em particular, a capacidade de identificar antecedentes de diferentes tipos de pronomes estão em desenvolvimento ao longo da escolaridade. De facto, em alguns dos pronomes e contextos linguísticos avaliados - por exemplo, na interpretação anafórica de pronomes demonstrativos e de pronomes relativos comparativamente a pronomes pessoais ou, dentro dos pronomes relativos, na compreensão de pronomes com função de sujeito em contraste com pronomes que ocorrem com a função de objeto -, esta capacidade não está ainda estabilizada no $3 .^{\circ}$ ciclo, ainda que os dados revelem um comportamento mais próximo entre os alunos deste ciclo e o grupo de adultos escolarizados.

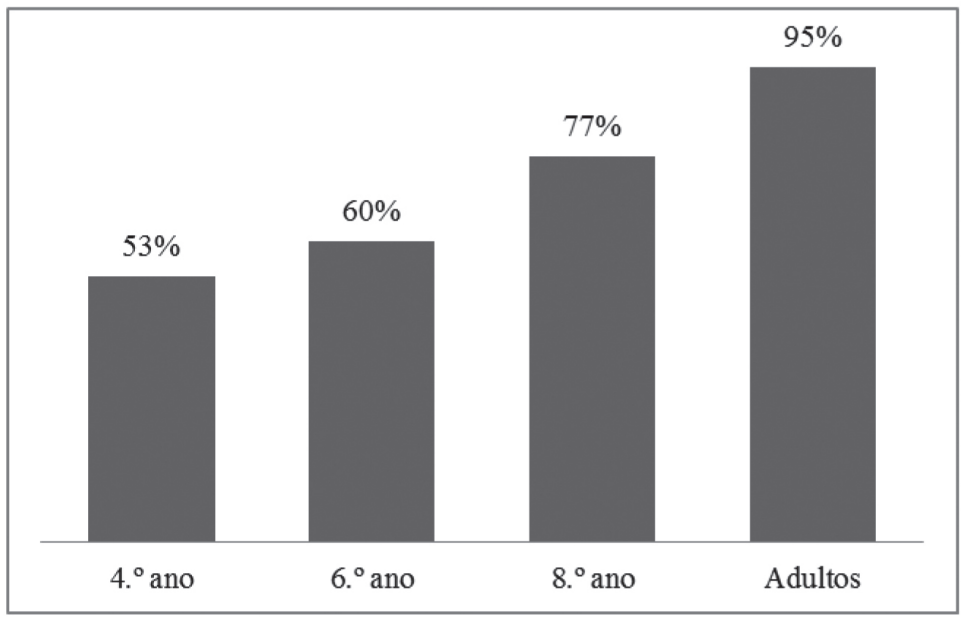

Gráfico 4 - Compreensão de pronomes anafóricos na leitura 
Por sua vez, no que se refere aos efeitos da intervenção didática, os resultados do grupo experimental, em comparação com os do grupo de controlo, sugerem que a capacidade de identificar antecedentes de pronomes pode ser potenciada através do desenvolvimento da consciência linguística sobre relações anafóricas logo a partir do $10^{\circ}$ ciclo. Da leitura do gráfico 5 , pode concluir-se que, apesar da diferença positiva registada em ambos os grupos entre os dois momentos de testagem (antes e após a intervenção didática), foi mais robusta a diferença entre as provas de diagnóstico e de avaliação de resultados observada no grupo experimental, sendo que este grupo obteve, para todas as variáveis estudadas, percentagens de respostas corretas acima dos $70 \%$.

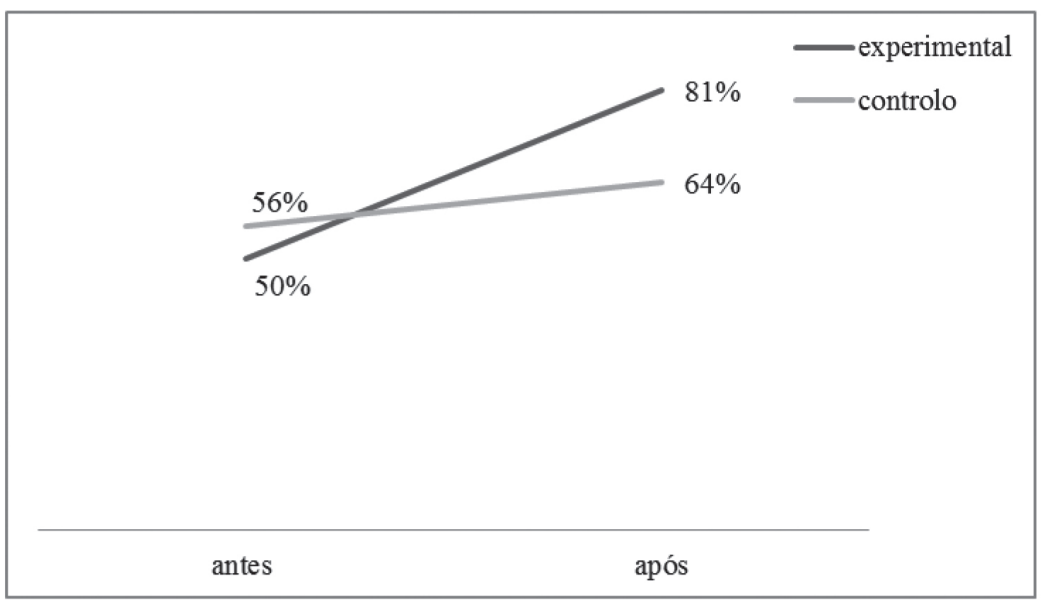

Gráfico 5 - Compreensão de pronomes anafóricos na leitura antes e após a intervenção

Adicionalmente, observou-se no grupo experimental uma convergência, global e individual, quanto aos desempenhos na prova do pós-teste e na prova nacional, o que permitiu concluir que a capacidade para compreender pronomes anafóricos na leitura, desenvolvida a partir de tarefas de consciencialização e explicitação linguística, pode ser positivamente relacionada com tarefas de compreensão global de leitura. Em síntese, os desempenhos dos alunos do grupo experimental antes e após a intervenção didática, por um lado, e após a intervenção didática e na prova nacional, por outro lado, sugerem, no que se refere à capacidade para compreender dependências referenciais, a existência de uma relação positiva entre os domínios da gramática, entendida como um processo de consciencialização e explicitação linguística, e da compreensão da leitura. Tal como no 
estudo sobre gramática e escrita, os dados obtidos neste segundo trabalho consolidam a importância de um ensino da gramática mais centrado no desenvolvimento da consciência linguística do que no ensino declarativo de conteúdos gramaticais.

\section{3 - Contributos dos estudos}

Da caracterização apresentada sobre dois percursos de investigação em didática da gramática, parece possível afirmar que este tipo de estudos, para além de reforçarem a evidência sobre o papel do conhecimento gramatical no desenvolvimento de outras competências - neste caso, da escrita e da compreensão da leitura -, são fundamentais na definição de estratégias a seguir no ensino da gramática e no contributo para a resposta a velhas questões de didática como "que gramática ensinar?" ou "como ensinar gramática?". Ancorados na investigação em aquisição da linguagem, dados como os apresentados são relevantes para caracterizar a natureza do conhecimento linguístico após a entrada para a escola e em diferentes momentos do percurso escolar, na medida em que permitem estabelecer uma distinção entre áreas do conhecimento linguístico que já se encontram estabilizadas (por exemplo, as adversativas e as concessivas factuais no $9 .^{\circ}$ ano ou os pronomes pessoais no $8 .^{\circ}$ ano) e domínios desse conhecimento que ainda estão em desenvolvimento e estabilização e que, por isso, mais poderão beneficiar de um trabalho de promoção de capacidades linguísticas desenvolvido em contexto escolar (por exemplo, alguns tipos de concessivas, como as hipotéticas e contrafactuais, e alguns tipos de pronomes, como os pronomes demonstrativos invariáveis ou os relativos de objeto).

Relativamente às áreas de conhecimento linguístico ainda em estabilização, o objetivo do ensino da gramática deve ser o desenvolvimento da consciência linguística, sendo fundamental que este tipo de trabalho possa ser desenvolvido logo a partir do $1 .^{\circ}$ ciclo, com tarefas adequadas. Importará esclarecer que, ao preconizar-se o desenvolvimento de estratégias que visem uma progressiva consciencialização e explicitação linguística, não se pretende a promoção de um trabalho que se esgote em aspetos metalinguísticos, mas a tomada de consciência sobre propriedades de diferentes estruturas linguísticas e o desenvolvimento de capacidades que envolvam a sua manipulação. Em nenhum caso, portanto, ensinar gramática é ensinar listas de termos e de definições.

Em síntese, em trabalhos como os apresentados, entende-se o ensino da gramática como um processo de explicitação do conhecimento linguístico, que envolve diferentes graus de consciência até ao conhecimento reflexivo e metalinguístico. Nesta perspetiva, o ensino da gramática tem um papel fundamental na promoção das áreas de conhecimento linguístico mais tardio 
e mais permeáveis ao ensino formal. No contexto português, são vários os trabalhos que apresentam um enquadramento como o que acabámos de caracterizar e esta perspetiva foi a adotada em momentos cruciais da formação de professores, como o Programa Nacional de Ensino do Português (PNEP) (cf. Freitas, Alves \& Costa 2007; Duarte 2008; Duarte 2011; Gonçalves, Guerreiro \& Freitas 2011) e a implementação dos Programas de Português de 2009 (cf. Costa, Cabral, Santiago \& Viegas 2011). Provavelmente, a questão do enquadramento teórico não é vista como um problema para quem partilha dos mesmos pressupostos; contudo, a didática da língua é um campo de confluência de muitas perspetivas, no qual se podem estabelecer muitas pontes com contributos de vários quadros teóricos. Para que essas pontes não constituam atropelos teóricos - ou um certo ecletismo turvo importa clarificar fronteiras: foi o que procurámos fazer.

\section{4 - O problema das pontes e outras considerações finais}

Na parte inicial deste artigo, procurou-se identificar algumas fronteiras, clarificando a relação que, no âmbito da linguística educacional, se pode estabelecer entre linguística e didática da gramática. Algumas fronteiras são assinaladas como passagens pouco úteis - o caso da lógica aplicacionista; outras são zonas de tensão - como as conceções de linguagem em diferentes teorias linguísticas; e outras, ainda, são áreas de confluência - como as perspetivas didáticas de ensino da gramática enquanto atividade reflexiva. Nestas áreas de confluência, são vários os autores que defendem a existência de um campo próprio de investigação em didática, que abrange a investigação sobre didática da gramática.

Além das fronteiras assinaladas, a natureza da investigação em didática caracteriza-se pelas pontes que estabelece entre teoria e prática. A validação de resultados de investigação em didática, incluindo a didática da gramática, depende, crucialmente, de uma reflexão dentro da sala de aula. Assim, num entendimento da didática da língua como campo autónomo de investigação, a rejeição de uma lógica aplicacionista passa pela revisão de critérios de validação de resultados e por uma alteração dos modelos de formação de professores, enquanto forma de disseminação desses resultados.

Em concreto, na investigação em didática, a validação de propostas deve passar menos por critérios quantitativos (típicos dos estudos experimentais) do que por abordagens interpretativas, resultantes de trabalho cooperativo entre investigadores e professores, em contextos de formação em que uns e outros alimentam a atualização científica através da validação dos resultados em práticas. Por exemplo, para uma didática da gramática, e consequentemente para a formação do professor, os estudos sobre desenvolvimento linguístico tardio podem contribuir para a definição 
das áreas prioritárias de desenvolvimento da consciência linguística, nos diferentes ciclos de ensino, e para a identificação das áreas em que já faz sentido construir com os alunos uma reflexão metalinguística. Neste sentido, a didática da gramática ocupar-se-á, antes de mais, de questões que são geradas pela prática, num modelo de investigação «integrado na prática», «inspirado pela prática»e «relevante para a prática» (Uccelli \& Snow 2008: 628). Concluindo, numa travessia bidirecional, a investigação deve servir e informar as práticas e a teoria deve ser reformulada e evoluir em resposta aos desafios dos contextos escolares.

\section{REFERÊNCIAS}

Alarcão, I. 2010. A constituição da área disciplinar de didática das línguas em Portugal. Linguarum arena. Vol. I. 1: 61-79.

Alarcão, I.; Andrade, A. I.; Araújo; Sá, M. H.; Melo-Pfeifer, S.; Santos, L. 2010. Intercompreensão e plurilinguismo: (re)configuradores epistemológicos de uma Didáctica de Línguas? Intercompreensão - Revista de Didáctica de Línguas: abordagens plurais e multimodais. 15: 9-26.

Amor, E. 1993. Didáctica do Português. Fundamentos e Metodologia. Lisboa: Texto Editora.

Batalha, J. 2017. Relações entre conhecimento explícito da língua e leitura. Compreensão de dependências referenciais no ensino básico. Dissertação de Doutoramento apresentada à Universidade Nova de Lisboa.

Cain, K.; Oakhill, J. 2009. Reading Comprehension Development from 8 to 14 years. The contribution of component skills and processes. In: R. K. Wagner; C. Schatschneider; C. Phythian-Sence (eds.). Beyond Decoding. The Behavioral and Biological Foundations of Reading Comprehension. New York: The Guildford Press.

Camps, A. 2012. La investigación en didáctica de la lengua en la encrucijada de muchos caminos. Revista iberoamericana de educación. 59: 23-41.

Camps, A. 2014. Metalinguistic activity in language learning. In: T. Ribas; X. Fontich; O. Guasch (eds.) Grammar at school. Research on metalinguistic activity in language education. Brussels: Peter Lang, 25-41.

Cassany, D.; Luna, M.; Sanz, G. 1994. Enseñar Lengua. Barcelona: Editorial Graó.

Cook, V. 1988. Chomsky's universal grammar: an introduction. Applied Language Studies. Oxford: Basil Blackwell.

Costa, A. 1991. Leitura: Compreensão e Processamento Sintáctico. Dissertação de Mestrado apresentada à Universidade de Lisboa.

Costa, A. 2010. Estruturas contrastivas: desenvolvimento do conhecimento explícito e da competência de escrita. Dissertação de Doutoramento apresentada à Universidade de Lisboa. 
Costa, A.; Alexandre, N.; Santos, A. L.; Soares, N. 2008. Efeitos de modelização no input: o caso da aquisição de conectores. In: S. Frota; A. L. Santos (orgs.). Textos Seleccionados do XXIV Encontro da Associação Portuguesa de Linguística. Évora 2007. Lisboa: APL, 131-142.

Costa, A.; Costa, M. A.; Gonçalves, A. 2017. Consciência linguística: aspetos sintáticos. In: M. J. Freitas; A. L. Santos (eds.). Aquisição de língua materna e não materna: Questões gerais e dados do português. Textbooks in Language Sciences 3. Berlin: Language Science Press, 409-438.

Costa, A.; Rodrigues, S; Sebastião, I. 2018. Para que serve a didática? In: L. G. Correia; R, Leão; S. Poças (orgs.). O Tempo dos Professores. Porto: CIIE. FPCEUP 811-827.

Costa, J.; Cabral, A.; Santiago, A.; Viegas, F. 2011. Guião de Implementação do Programa. Conhecimento Explícito. Lisboa: DGIDC. ME.

DEB. 2001. Currículo Nacional do Ensino Básico - Competências Essenciais. Lisboa: DEB. ME.

DGE. 2015. Programa e metas curriculares de Português do ensino básico. Lisboa: DGE. ME.

DGIDC. 2008. Dicionário terminológico para Consulta em Linha (DT). Consultado a 27 de abril de 2018: http://dt.dge.mec.pt/.

DGIDC. 2009. Programas de Português do Ensino Básico. Lisboa: DGIDC. ME.

Duarte, I. 1992. Oficina gramatical: contextos de uso obrigatório de conjuntivo. In: M. R. Delgado-Martins; D. R. Pereira; A. I. Mata; M. A. Costa; L. Prista; I. Duarte. Para a Didáctica do Português. Seis Estudos de Linguística. Lisboa: Colibri 165-177.

Duarte, I. 1998. Algumas boas razões para ensinar gramática. In: $A$ Língua Mãe e a Paixão de Aprender. Actas. Porto: Areal, 110-123.

Duarte, I. 2008. O conhecimento da lingua: desenvolver a consciência linguística. Lisboa: PNEP. DGIDC. ME.

Duarte, I. 2011. O conhecimento da língua: desenvolver a consciência lexical. Lisboa: PNEP. DGIDC. ME.

Fontich, X. 2016. L1 Grammar instruction and writing: metalinguistic activity as a teaching and research focus. Language and Linguistic Compass. 10/5: 238-254.

Fontich, X. 2018. Teaching and Learning Guide for: "L1 grammar instruction and writing: metalinguistic activity as a teaching and research focus". Language and Linguistic Compass. 12: 1-13.

Fontich, X.; García-Folgado, M. J. 2018. Grammar instruction in the Hispanic area: The case of Spain with attention to empirical studies on metalinguistic activity. Special issue: Working on grammar at school in L1 
education: Empirical research across linguistic regions. L1-Educational Studies in Language and Literature. 18: 1-39.

Freitas, M. J.; Alves, D.; Costa, T. 2007. O Conhecimento da língua: desenvolver a consciência fonológica. Lisboa: PNEP. DGIDC. ME.

Freitas, M. J.; Gonçalves, A.; Duarte, I. (eds.). 2010. Avaliação da consciência linguística. Aspectos fonológicos e sintácticos do português. Lisboa: Colibri.

Gonçalves, F.; Guerreiro, P.; Freitas, M. J. 2011. Conhecimento da língua. Percursos de desenvolvimento. Lisboa: PNEP. DGIDC. ME.

Honda, M.; O’Neil, W.; Pippin, D. 2010. On promoting linguistics literacy: Bringing language science to the English classroom. In: K. Denham; A. Lobeck (eds.). Linguistics at school: Language awareness in primary and secondary education. Cambridge: Cambridge University Press, 175-188.

Hudson, R. 1992. Teaching Grammar. A Guide for the National Curriculum. Oxford: Blackwell.

Jolibert, J. (coord.). 1988. Former des Enfants Producteurs de Textes. Paris: Hachette-Écoles.

Karmiloff-Smith, A. 1992. The child as linguist. In: Beyond modularity. A Developmental perspective on cognitive science. Cambridge, Mass: MIT Press/Bradford Books, 31-63.

Leal, T. F.; Roazzi, A. 1999. Uso de pistas linguísticas na leitura: análise do efeito da consciência sintático-semântica sobre a compreensão de textos. Revista Portuguesa de Educação. 12(2): 77-104.

Oliveira, R. P.; Quarezemin, S. 2016. Gramáticas na escola. Petrópolis: Editora Vozes.

O' Neil, W. (2010). Bringing linguistics into the school curriculum: not one less. In: K. Denham; A. Lobeck (eds.) Linguistics at school. Language Awareness in Primary and Secondary Education. Cambridge: Cambridge University Press, 24-34.

van Rijt, J.; P.A. Coppen 2017. Bridging the gap between linguistic theory and L1 grammar education - experts' views on essential linguistic concepts. Language Awareness. 26: 360-380.

Sim-Sim, I.; Duarte, I.; Ferraz, M. J. 1997. A Língua Materna na Educação Básica. Lisboa: DEB. ME.

Spolsky, B. 1978. Educational Linguistics: an introduction. Rowley, MA: Newbury House.

Spolsky, B. 1999. Introduction to the field. In: B. Spolsky (ed.) Concise Encyclopedia of educational Linguistics. Oxford: Elsevier, 1-6.

Spolsky, B. 2008. Introduction: what is Educational Linguistics? In: B. Spolsky; F. M. Hult (eds.). The handbook of educational linguistics. Oxford: Wiley-Blackwell, 1-9. 
Ucelli, P.; Snow, C. 2008. A research agenda for Educational Linguistics. In: B. Spolsky; F. M. Hult (eds.). The handbook of educational linguistics. Oxford: Wiley-Blackwell, 626-642. 